\title{
Ministerialidad laical y secularidad presbiteral versus secularización del laicado y sacralización del presbiterado
}

\author{
Jesús Martínez Gordo, \\ Facultad de Teología de Vitoria-Gasteiz.
}

Los momentos más fecundos de la teología católica han sido aquellos en los que ésta ha sabido mantener el equilibrio - permanentemente inestable - entre verdades aparentemente contradictorias, pero nucleares en la revelación cristiana.

Los concilios cristológicos y trinitarios avalan la entidad veritativa que presenta la perspectiva "católica" y muestran, por ejemplo, la improcedencia de sacrificar el Jesús histórico al Cristo de la fe y de éste último en favor del primero. Con lenguaje menos formal y más contemporáneo: si el Jesús histórico sin el Cristo de la fe se desliza por la pendiente del masoquismo irredento, el Cristo de la fe sin el Jesús histórico se adentra en una Arcadia supuestamente tan feliz como inconsciente del dolor y de la muerte que atenaza la existencia. Ni una ni otra extrapolación se hacen cargo de la "catolicidad" de la revelación cristiana y ninguna de ellas se aproxima a su corazón. Solo una teología que acentúe - legítimamente, por cierto- el Jesús histórico o el Cristo de la fe, sin renunciar a articular el uno con el otro, puede asomarse al misterio de Dios, a su luz, belleza y amor.

Cuando se analiza la recepción del Vaticano II se constata la dificultad que tienen algunos sectores de la iglesia para acogerlo sin alterar el equilibrio permanentemente inestable - propio de lo "católico"- que ha pretendido y, muy frecuentemente, ha logrado formular dicho concilio. Se trata, obviamente, de un equilibrio que, al encontrarse referido a la revelación del misterio de Dios en Jesucristo, es permanentemente inestable y, por ello, espacio abierto a diferentes y complementarias aproximaciones. La "catolicidad", así comprendida, se conjuga perfectamente con la pluralidad, a la vez que rehúye las acentuaciones unilaterales y las descalificaciones prematuras. 
Esto es perfectamente apreciable, al menos, en cinco grandes apartados referidos a la relación entre el primado y la colegialidad; la iglesia universal y la local; la revelación y la fe o la escritura, la tradición y el magisterio; la iglesia y el mundo; y, también, a la relación entre el laicado y el ministerio ordenado.

Son cuestiones importantes en las que se está jugando no solo la recepción eclesial del Vaticano II, sino también el mismo futuro de la iglesia, ya que el descuido o la escasa atención a esta "catolicidad" tiene indudables consecuencias doctrinales y pastorales.

Concretamente, el análisis de la deseable articulación entre ministerialidad laical y secularidad presbiteral -intentando superar la "sacralización" del sacerdocio ministerial y la "secularización" del laicado- permite mostrar la importancia de una metodología "católica" no sometida, por tanto, a diagnósticos socioeclesiales propuestos por el sector mayoritario de la curia vaticana, tan comprensibles (por los temores que canalizan e incuban) como criticables (por el modelo de iglesia y de cristiano que favorecen).

\section{La ministerialidad laical}

En el origen de la tipificación como "ministerio" del servicio pastoral que prestan los laicos se encuentran — además del fundamento bautismal recuperado por el Vaticano II - tres importantes aportaciones: el motu propio "Ministeria quaedam" de Pablo VI; la autocrítica de su teología sobre el laicado por parte de Y. M. Congar; y la caracterización de lo que es un ministerio, por parte de las conferencias episcopales francesa (1973) y alemana (1977 y 1978).

Curiosamente, las primeras reticencias a la tipificación como ministerial del servicio pastoral prestado por algunos laicos también se deben a Pablo VI y - de su mano- al sínodo de obispos del año 1971. Él es quien inaugura una consideración recelosa que se va a consolidar en la encíclica postsinodal "Christifideles laici” de 1988 y que culmina en la Instrucción Interdicasterial de 1997.

\section{El sínodo episcopal de 1971}

Pablo VI tiene la convicción de que el ministerio ordenado $-y$, particularmente, el presbiterado - no ha sido debidamente tratado en el Vaticano II. Avalarían semejante conclusión el espectacular aumento de los abandonos de presbíteros y la publicación de un diagnóstico de la congregación para la doctrina de la fe según el cual las causas de la crisis serían la fe inestable y el celibato. Estas dos constataciones determinan que Pablo VI convoque al sínodo de obispos de 1971 para abordar la cuestión del sacerdocio ministerial ${ }^{1}$.

1. E. Colagiovanni, Le defezioni dal ministero sacerdotale, Vaticano, 1971, p. 262. Cfr. M. Alcalá, “ ¿Sacerdotes célibes y sacerdotes casados?”, Razón y Fe (1971), pp. 384400. Cfr. M. Alcalá, Historia del sínodo de los obispos, Madrid, 1996, pp. 71-97. 
La celebración del sínodo viene precedida de una tensa relación entre la Comisión Teológica Internacional y la curia vaticana a causa de la conceptualización teológica que se ha de emplear para referirse al presbiterado. La Comisión Teológica se decanta por seguir usando la expresión "sacerdocio ministerial" del Concilio Vaticano II (PO II, 1,4) con una doble finalidad: visualizar -incluso semánticamente - una concepción más articulada del presbiterado con los ministerios laicales y acentuar su misión evangelizadora que, ciertamente, comporta una dimensión litúrgica y sacral, pero que no se agota en ella.

La curia vaticana propone abandonar esta conceptualización (y las opciones teológicas y eclesiológicas que comporta) en favor de la de "ministerio sacerdotal" porque entiende que es menos funcional que la de "sacerdocio ministerial", a la vez que permite resaltar mucho más el carácter sagrado del presbiterado, algo que está quedando peligrosamente eclipsado también por la eclosión de los ministerios laicales y por los discursos teológicos -inaceptablemente homogeneizantes - que se están formulando entre estos ministerios y el ordenado.

Tras un complejo proceso de reconducción del debate entre la curia vaticana y la Comisión Teológica Internacional, se abandona la expresión "sacerdocio ministerial" en favor de la de "ministerio sacerdotal". Es cierto que ambas acentuaciones se complementan mutuamente, pero también lo es que provocan distintas evaluaciones, tanto prácticas como teóricas, y que suscitan diferenciadas comprensiones del ministerio ordenado.

Sorprendentemente, la mayor parte de los obispos participantes en el sínodo no se percatan del alcance teológico y eclesiológico que encierra el cambio del término. Entienden que es una cuestión de escasa entidad o meramente conceptual. Sin embargo, es un cambio que abre las puertas a una recepción involutiva tanto de la teología sobre el ministerio ordenado como sobre el laicado². A partir de ahora, lo que preocupa es recuperar la sacralidad perdida por el presbiterado en el postconcilio y asignar la secularidad como misión propia - cuando no, exclusiva- del laicado.

Es cierto que este sínodo ha pasado a la historia como aquel en el que se retoma a fondo la opcionalidad del celibato y la ordenación de varones casados (abriéndose tímidamente la puerta a esta última modalidad). Pero también lo es que los padres sinodales aconsejan que los presbíteros no ejerzan profesiones civiles ( $\mathrm{y}$ no solo como consecuencia del proceso sacralizador incoado, sino también en nombre de la optimización de recursos humanos) y que se limiten sus actividades civiles hasta acabar prácticamente reducidas a una genérica defensa de los derechos humanos.

Obviamente, los padres sinodales no cuestionan formalmente la secularidad del presbiterado recuperada por el Vaticano II, pero recelan de ella y piden - sin

2. Sínodo de los obispos 1971, Documentos, Salamanca, 1972, pp. 13 y ss. 
negarla - una mayor atención a las demandas litúrgicas, sacramentales, catequéticas y a la presidencia de la comunidad cristiana. La promoción de la justicia y la posibilidad de una presencia transformadora en el mundo - algo que el concilio había reivindicado como tarea inscrita en el corazón del ministerio ordenado- empiezan a ser reconsideradas desde la necesidad de recuperar la sacralidad perdida $y$, por tanto, comienzan a ser respetuosamente aparcadas.

Pero el cambio terminológico adoptado por la curia vaticana, y acríticamente asumido por los padres sinodales, también afectará a la recepción de la teología del laicado, ya que si bien es cierto que solo una pequeña parte de ellos recela de considerar el servicio pastoral que los laicos prestan como "ministerio", es igualmente cierto que se pone la primera piedra para diagnosticar, más adelante, que semejante tipificación también contribuye a la disolución de la identidad y espiritualidad presbiteral. A partir de este sínodo episcopal se ponen las bases para activar no solo un proceso - por cierto, nada conciliar - de "sacralización" del presbiterado, sino también de "secularización" del laicado, pues se comienza a enfatizar que lo "propiamente" suyo es la presencia en el mundo.

Sin embargo, esta irrupción de una lectura sacralizante del presbiterado no puede ocultar que para la gran mayoría de los padres sinodales es incuestionable la promoción e institucionalización de los ministerios laicales en las comunidades cristianas, sin dejar de seguir buscando, por ello, una más equilibrada articulación con el presbiterado. De hecho, no faltarán padres sinodales que apunten la conveniencia de contar con unos presidentes de las comunidades que, ordenados, ejerzan su cargo temporalmente; una audaz propuesta anticipada por H. Küng ${ }^{3}$, W. Kasper ${ }^{4}$ e Y. Congar ${ }^{5}$, y posteriormente desarrollada por C. Voge $^{6}$, P. Grelot ${ }^{7}$, C. Vagaggini ${ }^{8}$, A. Lemaire ${ }^{9}$, H. Denis ${ }^{10}$, L. Boff ${ }^{11}$, C. Duquoc ${ }^{12}$ y J.

3. Cfr. H. Küng, La Iglesia, Barcelona, 1968.

4. Cfr. W. Kasper, "Acentos nuevos en la comprensión dogmática del servicio sacerdotal", Concilium 43 (1969).

5. Cfr. Y. Congar, "Quelques problèmes touchant les ministères", NRT 93 (1971), pp. 785-800.

6. Cfr. C. Vogel, "Le ministre charismatique de l'eucharistie. Approche rituelle", en Ministères et célébration de l'eucharistie (colección Studia Anselmiana, 61), Roma, 1973, pp. 191-209.

7. Cfr. P. Grelot, "Réflexions générales autour du thème du symposium: Le ministre de l'eucharistie", en Ministères et célébration de l'eucharistie, óp. cit., pp. 17-93.

8. Cfr. C. Vagaggini, "Possibilità e limiti del riconoscimento dei ministri non cattolici. Riflessioni a partire dalla prassi della 'economia' e dalla dottrina del 'carattere", en Ministères et célébration de l'eucharistie, óp. cit., pp. 250-320.

9. Cfr. A. Lemaire, Les ministères dans l'Église, París, Cerf, 1974, pp. 123-124. "

10. Cfr. H. Denis, Des sacrements et des hommes, Lyon, 1975, pp. 157-160.

11. Cfr. L. Boff, Eclesiogénesis. Las comunidades de base reinventan la Iglesia, Santander, 1982.

12. Cfr. C. Duquoc, "Théologie de l'Église et crise du ministère", Études, janvier (1979), pp. 101-113. 
Moingt ${ }^{13}$. Es una propuesta reactivada recientemente - con desigual fortunapor los dominicos holandeses (Kerk en Ambt. Onderweg naar een kerk met toekomst $)^{14}$, F. Lobinger ${ }^{15}$ y P. Tihon ${ }^{16}$, entre otros.

\section{La carta apostólica "Ministeria quaedam" de Pablo VI (1972)}

Si es cierto que Pablo VI pone las bases para recuperar una concepción más sacral del presbiterado, también lo es que ha pasado a la historia como el papa que propició un espectacular desarrollo de los ministerios laicales - particularmente, en las iglesias alemana, francesa y helvética- gracias al "motu propio" "Ministeria quaedam" (1972).

La carta apostólica de Pablo VI es importante porque establece una distinción entre los ministerios instituidos (que pasan a ser dos: el lectorado y el acolitado) y los "confiados" (que pueden ser muchos y cuyo reconocimiento descansa en las necesidades de las respectivas iglesias locales). Es una tipificación ministerial que será respetada por los papas posteriores y, más recientemente, por conferencias episcopales tan relevantes como la brasileña ${ }^{17}$ y la estadounidense ${ }^{18}$.

Los críticos subrayan que este "motu propio" presenta una cierta estrechez de miras al erigir únicamente dos ministerios instituidos (lector y acólito), además de reservarlos exclusivamente a los varones ${ }^{19}$.

Sin embargo, esta acertada y oportuna consideración crítica no eclipsa la importancia que Pablo VI concede a las iglesias locales en la promoción de otros posibles ministerios (catequista, animación litúrgica, consejero conyugal, ayuda a novios,

13. Cfr. J. Moingt, "Service et lieux d'Église", Études, juin (1979), pp. 835-849.

14. Cfr. "'Kerk en Ambt', Iglesia y Ministerio. Interesantes iniciativas de los dominicos holandeses", 10 de diciembre de 2007. Disponible en http://www.redescristianas.net $/ 2007 / 12 / 10 / \%$ E2\%80\%9Ckerk-en-ambt\%E2\%80\%9D-iglesia-y-ministeriointeresantes-iniciativas-de-los-dominicos-holandeses/. Cfr. J. Perea, "Arriesgada propuesta de los dominicos holandeses ante la escasez de presbíteros", Iglesia Viva 236 (2008), pp. 127-134. Presentación del texto y de algunas reacciones criticando acertadamente cuestiones menores, pero sin afrontar la cuestión de fondo.

15. Cfr. F. Lobinger, Priests for Tomorrow, Quezon City, Philippines, 2004. Cfr. ibíd., "Derecho de la comunidad a un pastor. VI: Países africanos", Concilium 153 (1980).

16. Cfr. P Tihon, "Sur l'animation des communautés catholiques. La présidence de l'eucharistie, un débat clos?", Revue Théologique de Louvain 39 (2008), pp. 492-519.

17. Cfr. Conferência Nacional dos Bispos do Brasil, Missẫo e ministérios dos cristãos leigos e leigas, Edição aprovada na $37^{\mathrm{a}}$ Assembléia Geral da CNBB, Itaici, SP, 22 de abril de 1999.

18. Cfr. United States Conference of Catholic Bishops, Co-Workers in the Vineyard of the Lord: A Resource for Guiding the Development of Lay Ecclesial Ministry, Washington D. C., 2005.

19. Cfr. Sagrada Congregación para la Disciplina de los Sacramentos, Instrucción 'Fidei custos' sobre los ministros extraordinarios de la comunión, Roma, 1969. 
pastoral con jóvenes, caridad y justicia, coordinador parroquial, etc.). De hecho, es la decisión magisterial más definitiva para la explosión ministerial que va a experimentar la iglesia en esta primera fase de la recepción conciliar. Y también de la tipificación como "ministerio" del servicio pastoral que prestan los laicos.

\section{Y. M. Congar: autocrítica y binomio "ministerios-comunidad"}

El posicionamiento favorable de Pablo VI viene acompañado de la autocrítica a la que somete Y. M. Congar su teología del laicado. Tal revisión le lleva a abandonar el binomio "sacerdocio-laicado" que empleaba en Jalons pour une théologie du laïcat (1951) y a proponer el de "ministerios o servicios-comunidad" como el más adecuado para comprender la relación entre el presbiterado y la institucionalización de los diferentes carismas laicales en el seno de la comunidad cristiana.

Con palabras del mismo padre Congar: "la Iglesia de Dios no se construye solamente por los actos del ministerio oficial del presbiterado, sino por una multitud de servicios diversos más o menos estables u ocasionales, más o menos espontáneos o reconocidos y, eventualmente, hasta consagrados por la ordenación sacramental (catequesis, lector, visita a presos y enfermos, responsable de acción católica, de misiones, ayuda a parados, emigrantes...). Existen, pero hasta ahora ni se los había llamado por su verdadero nombre, el de ministerios, ni se les había reconocido su puesto y su estatuto en la eclesiología. La pareja decisiva no es precisamente 'sacerdocio-laicado' que yo usaba en Jalons pour une théologie du laïcat (1951), sino más bien 'ministerios o servicios-comunidad" "20.

Y. M. Congar es el primer teólogo que aplica, como consecuencia de tal revisión en el postconcilio, la expresión "ministerios" al laicado (algo que todavía no se encuentra en el Vaticano II). Se trata de una tipificación que tiene una excepcional acogida en la comunidad cristiana y que va a llegar hasta nuestros días, a pesar de los intentos de algunos sectores - sobre todo de la curia vaticana- por reservar su empleo para referirse únicamente al presbiterado.

\section{El "ministerio" según los obispos franceses (1973)}

Si a Pablo VI se debe la aparición, por primera vez en la historia de la iglesia, de la expresión "ministerios confiados a los laicos", a los obispos franceses se debe la formulación magisterial más importante en esta época sobre lo que se ha de entender por "ministerio" 21.

20. Y. M. Congar, Ministerios y comunión eclesial, Madrid, 1973, pp. 11.31.19.

21. Cfr. J. Martínez Gordo, Los laicos y el futuro de la iglesia. Una revolución silenciosa, Madrid, PPC, 2002, pp. 91 y ss. 
Es una precisión que ofrecen, así lo indican, tratando de superar un uso lato del mismo: la misión global de la Iglesia o el servicio espontáneo y ocasional de un cristiano determinado. Los obispos franceses descartan esta acepción y se decantan por su uso teológico, lo que les lleva a designar como ministerios

- los servicios definidos, de importancia vital, que llevan consigo una verdadera responsabilidad, reconocidos por la iglesia local y que suponen una cierta duración;

- los "instituidos" por un acto litúrgico; y

- los confiados mediante ordenación (diaconado, presbiterado, episcopado).

No está de más recordar que una formulación de este calado viene facilitada por el asesoramiento de Y. M. Congar.

Estas tres aportaciones, de Pablo VI, de Y. M. Congar y de la conferencia episcopal francesa, abren las puertas a un espectacular desarrollo de los ministerios laicales: de una manera más llamativa y conocida en el viejo continente (particularmente en Alemania, Francia y Suiza) y menos conocida, pero mucho más importante, en las iglesias del Tercer Mundo ${ }^{22}$.

\section{La conferencia episcopal alemana}

La conferencia episcopal alemana es una de las primeras que ofrece en 1977 una reflexión sistematizada sobre la identidad de demás laicos, así como sobre la oportunidad de armonizar dicha identidad laical con la de los presbíteros, diáconos; una cuestión que se va a convertir en capital en las décadas siguientes ${ }^{23}$.

$\mathrm{Al}$ año siguiente dan a conocer el primer estatuto jurídico en el que se tipifican las diferentes clases de laicado profesionalizado, a la vez que se indican sus respectivas áreas de compromiso, su proceso de formación, el tipo de contrato, el salario, etc. ${ }^{24}$.

\section{Unidad sin confusión}

Sin embargo, estos primeros y matizados posicionamientos no van a poder evitar la apertura del debate sobre la identidad ministerial del laicado y del mi-

22. Cfr. ibid., pp. 240, 91-137, 241-283.

23. Cfr. Die Deutschen Bischöfe, Weiner Diözesanblatt, IV, 1977 [Traducción francesa: "Le prêtre, le diacre et le laic dans la pastorale. Déclaration de la Conférence épiscopale allemande", DC 1721, 5 juin (1977), pp. 517-522].

24. Cfr. Grundsätze der Deutschen Bischofskonferenz vom 2. März 1977. Cfr. Die Deutschen Bischöfe, Rahmenstatut der Deuschen Bischofkonferenz vom Herbst 1978 für Pastoralreferenten (innen), Archiv für Katholisches Kirchenrecht/AKK, 147, 1978, pp. 486 y ss. 
nisterio ordenado, asunto que va tener en E. Schillebeeckx y L. Boff a dos de sus exponentes más criticados ${ }^{25}$.

Sus escritos suscitan la cuestión del "poder" del laicado en la Iglesia, algo que ocasiona diversas intervenciones de la Santa Sede. En el caso de E. Schillebeeckx se solucionó sin condena alguna, y en el de L. Boff comportó la calificación de enseñanza "que pone en peligro la doctrina de la fe"26.

Estos dos conflictos han condicionado, quizá más de lo que parece, el desarrollo posterior de las regulaciones sobre los "ministerios confiados a laicos" por el riesgo de confusión que podían acarrear entre el ministerio ordenado y el no ordenado ${ }^{27}$.

La mayoría de los teólogos que abordan la cuestión de la identidad de los laicos con encomienda pastoral explícita o implícita (que son pocos) se posicionan a favor de entender que siguen siendo laicos. Tal es el caso de S. Dianich, B. Forte, H. J. Pottmeyer, M. Kehl, J. Manzanares y R. Arnau. Sin embargo, no faltan tampoco quienes sostienen que, al ejercer un ministerio pastoral, no son puramente laicos en el sentido tradicional de la palabra. En este grupo se encuentran, entre otros, K. Rahner, Y. Congar, G. Philips, D. Borobio, B. Sesbouié, A. Borras, M. Pelchat, W. Kasper y J. Rigal.

La nota teológica de los obispos franceses apunta en la misma dirección cuando sostiene que los laicos con encomienda pastoral "son constituidos en una nueva responsabilidad que les hace comprometer de una forma particular el signo sacramental de la Iglesia en el mundo"28.

\section{Christifideles Laici (1988): la incómoda ministerialidad laical}

La cuestión de la ministerialidad del laicado es retomada en el sínodo de 1987. Las intervenciones en el aula sinodal vuelven a agruparse claramente en dos tendencias: una, más preocupada por salvaguardar la identidad del ministerio ordenado, y, otra, partidaria de favorecer una mayor y creciente intervención ministerial del laicado.

Sin embargo, en esta ocasión - y a diferencia de lo sucedido después del sínodo de 1971 - Juan Pablo II presta más atención a la primera de las sensibilidades. Es cierto que señala la oportunidad de "reconocer y promover los ministerios, oficios y funciones de los fieles laicos, que tienen su fundamento sacramental en el Bautismo y en la Confirmación, y para muchos de ellos, además en el

25. Cfr. E. Schillebeeckx, El Ministerio eclesiástico, Madrid, 1983; L. Boff, Iglesia: carisma y poder, Santander, 1982.

26. Cfr. Enchiridion Vaticanum 9:830-836 (Schillebeeckx); 9:1421-1432 (Boff).

27. Cfr. S. Pié, "Los ministerios confiados a los laicos", Phase 224 (1998), p. 145.

28. Cfr. Les Évêques de France, Bureau d'Études Doctrinales, Les Ministres ordonnés dans une Église-communion, París, 1993, pp. 51-59. 
Matrimonio" 29 . Pero también lo es que se manifiesta particularmente receptivo a las voces críticas que llaman la atención sobre el uso indiscriminado del término "ministerio" porque lleva a confundir $-\mathrm{y}$, a veces, a igualar - el sacerdocio común y el sacerdocio ministerial. También lo es a aquellas otras que denuncian la escasa observancia de ciertas leyes y normas eclesiásticas, la interpretación arbitraria del concepto de "suplencia" 30 , la tendencia a la "clericalización" de los fieles laicos y el riesgo de crear de hecho una estructura eclesial de servicio paralela a la fundada en el sacramento del orden ${ }^{31}$.

Los padres sinodales han solicitado - señala Juan Pablo II - que se indiquen con toda claridad "tanto la unidad de misión de la Iglesia, en la que participan todos los bautizados, como la sustancial diversidad del ministerio de los pastores, que tiene su raíz en el sacramento del Orden, respecto de los otros ministerios, oficios y funciones eclesiales, que tienen su raíz en los sacramentos

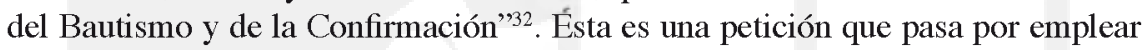
una terminología más precisa, así como por recordar que la secularidad es la nota más propia y característica del laicado.

Es una observación que llama la atención porque se formula a partir de un diagnóstico que - como el reseñado - se presta a acabar justificando una eclesiología preconciliar y segín la cual los asuntos de la Iglesia eran competencia exclusiva de los ministros ordenados.

Esta encíclica postsinodal marca el paso de una recepción creativa de la teología conciliar sobre el laicado a otra más preocupada por proteger el ministerio ordenado y el actual modelo de ejercicio del mismo. A partir de ahora, la identidad del ministerio ordenado va a ser abordada por la curia vaticana no solo en confrontación con una supuesta "protestantización" de la misma y con una desmedida adaptación a las demandas de la modernidad (secularización), sino también en relación con las nuevas formas de ministerialidad laical. La teología centrada en la corresponsabilidad del laicado es objeto de un sinfín de cautelas.

\section{La Instrucción Interdicasterial de 1997}

La Instrucción Interdicasterial de 1997 sobre la colaboración de los fieles laicos con el ministerio sacerdotal se hace eco de este ambiente ${ }^{33}$. El decreto

29. Juan Pablo II, Exhortación apostólica post-sinodal Christifideles laici de su santidad Juan Pablo II sobre vocación y misión de los laicos en la iglesia y en el mundo, $\mathrm{n}^{\circ}$ 23, Roma, 1988.

30. El Concilio Vaticano II habló, según los casos, de "suplencia" o "colaboración" de laicos con el ministerio presbiteral.

31. Cfr. Juan Pablo II, óp. cit., n. ${ }^{\circ} 23$.

32. Ibidem.

33. Cfr. "Instrucción Interdicasterial 'Ecclesiae de mysterio', sobre algunas cuestiones 
propone dejar de aplicar la expresión "ministerio" al servicio prestado por los laicos y se decanta por el término de "colaboración". Es así como acaba distinguiendo en la única misión de la Iglesia dos ámbitos: el espiritual y el temporal. Obviamente, el presbiterado viene reconducido al primero y el laicado queda destinado al compromiso secular. Incluso, llega a emplearse la expresión de "consecratio mundi", algo que el concilio quiso evitar para hablar la misión del laico en el mundo.

Fijado ese punto de partida, ya no extraña que defienda - en esta ocasión, abiertamente - una concepción más sacral que "sacerdotal" y ministerial del presbiterado. Por eso, propone abandonar la tipificación del servicio laical como "ministerio" en favor de la "colaboración", a pesar de que también señala la existencia de dos tipos de ministerios: los ordenados y los bautismales, fundados, estos últimos, sobre la iniciación cristiana y sobre el sacerdocio universal. Y a pesar de que posteriormente llama "ministros extraordinarios" (Art. 1, par. 3) a los laicos que desempeñan responsabilidades pastorales en virtud de un envío en misión. Es evidente que el empleo de tal terminología no agrada a la curia vaticana, que prefiere orillarlo.

Sin embargo, la Instrucción Interdicasterial no anula ni dogmática, ni teológica ni disciplinarmente el uso del término "ministerio" para las funciones eclesiales asumidas por los laicos, aunque lo utilice con restricciones y cautelas y eluda sistemáticamente su empleo. Que guste más o menos o que se pretenda sumir en el olvido el concepto de "ministerio" aplicado al servicio pastoral prestado por los laicos es una cuestión que no invalida su legítimo uso también en la actualidad. De hecho, el mismo papa Juan Pablo II lo empleará cuatro años más tarde cuando sostenga que "junto con el ministerio ordenado, pueden florecer otros ministerios, instituidos o simplemente reconocidos, para el bien de toda la comunidad"34.

De todas formas, a partir de ahora, "lo propio" del sacerdocio ministerial se concentra en la presidencia de la comunidad cristiana, en el culto y en la palabra; por supuesto, con la "colaboración" de algunos laicos que "participan" en dichas tareas y funciones. Como contrapartida, la posibilidad de una presencia -incluso profesional - del presbítero en el mundo se diluye. Las grandes perdedoras de esta recepción conciliar son la secularidad del presbiterado y, en ocasiones, la misma promoción de la justicia y de la caridad.

acerca de la colaboración de los fieles laicos con el ministerio de los sacerdotes" (15 de agosto de 1997), AAS 89 (1997).

34. Juan Pablo II, Carta apostólica Novo millennio ineunte del sumo pontífice Juan Pablo II al episcopado, al clero y a los fieles al concluir el gran jubileo del año 2000, n. ${ }^{\circ}$ 46, Ciudad del Vaticano, 2001. 
El papa Benedicto XVI ha insistido en la dirección marcada por la Instrucción Interdicasterial recordando - en la promulgación del año sacerdotal - que el anuncio del Evangelio y la administración de los sacramentos son "las dos columnas fundamentales del servicio sacerdotal" 35 .

Hay, sin embargo, dos importante excepciones a esta línea de fondo en los casos de los obispos de Brasil y de los Estados Unidos.

\section{La conferencia episcopal de Brasil}

Los prelados brasileños reconocen que su planteamiento ha experimentado una evolución, ya que abordaron en un primer texto la relación entre ministerialidad laical y ministerio ordenado dando un peso excesivo a la teología del ministerio ordenado. Sin embargo, en la redacción finalmente aprobada ha primado la vocación fundamental del laico como miembro del pueblo de Dios y corresponsable de la misión eclesial. Semejante subrayado no solo les ha llevado a superar el riesgo de subsumir la ministerialidad laical en la ordenada - aparcando la separación que favorecía tal planteamiento-, sino que les ha permitido recuperar la corresponsabilidad de los laicos - de raíz bautismal - en toda la misión y acción evangelizadora de la Iglesia, algo que pasa por una correcta articulación entre ministerialidad y secularidad ${ }^{36}$.

Es así como quieren superar una inaceptable yuxtaposición no solo entre la ministerialidad ordenada y la laical, sino también entre el compromiso ministerial y la presencia secular. Y si es de recibo todo acento teológico que salga al paso de cualquier disolución de ambas clases de ministerialidad, también lo es toda propuesta que las conciba en referencia a la misión de la Iglesia, sacramento de salvación del mundo.

"La misión evangelizadora de la Iglesia - recuerdan - es realizada por todo el Pueblo de Dios, con su diversidad de vocaciones y ministerios (ministros ordenados, consagrados y consagradas, laicos y laicas) que se armonizan, sin confundirse, en la realización de la tarea común" 37 . Esto quiere decir que "los ministerios son siempre ministerios en la Iglesia y para la Iglesia, pero siempre Iglesia sacramento de salvación y liberación de todo el hombre y de todos los hombres en una única historia de salvación" 38.

35. Zenit 090701.

36. Cfr. Conferência Nacional dos Bispos do Brasil, Missâo e ministérios dos cristâos leigos e leigas, óp. cit. [Traducción al español: Conferencia Nacional de Obispos de Brasil, Misión y ministerios de los cristianos laicos, CNBB, 2000, Bogotá, Celam, 2003], "Presentaçao".

37. Ibid., n. ${ }^{\circ} 62$.

38. Ibid., n. ${ }^{\circ}$ 90. Cfr. ibid., n. ${ }^{\circ}$ 83: Obviamente, un ministerio es un carisma puesto al servicio de la comunidad y de su misión en el mundo y en la Iglesia. Es bien sabido que cualquier carisma deja de ser una gracia únicamente personal cuando es reconocido y acogido por la Iglesia. 
La radicación de toda la ministerialidad en la misión salvífica y liberadora de la Iglesia les lleva a tipificar - prolongando las aportaciones de Pablo VI, Y. M. Congar y de la conferencia episcopal francesa - las diferentes clases de ministerios en cuatro categorías: "reconocidos", "confiados", "instituidos" y "ordenados".

Entienden por ministerios "reconocidos" aquellos que están vinculados a un servicio significativo para la comunidad, pero que, en cuanto tal, no son permanentes. Por ello, esta clase de ministerios pueden desaparecer cuando cambien las circunstancias.

Por su parte, son ministerios "confiados" aquellos que se confieren por un gesto litúrgico simple o por alguna forma canónica (los ministros de la sagrada comunión, del bautismo o de otra clase cuya iniciativa corresponde a la autoridad en la Iglesia).

En cambio, son ministerios "instituidos" aquellos que se otorgan a través de un rito litúrgico llamado "institución".

Finalmente, en los ministerios "ordenados" el carisma es reconocido y conferido a su portador a través de un sacramento específico (el sacramento del orden). Esta clase de ministerio no es la "síntesis de los ministerios", sino el "ministerio de síntesis". Su carisma específico es la presidencia y, por tanto, la animación, coordinación y el discernimiento de los carismas con la participación indispensable de toda la comunidad.

A continuación, los obispos brasileños subrayan que los ministerios no se limitan al ámbito del culto, de la palabra o de la coordinación eclesial. Es incuestionable que la Iglesia está en el mundo y que uno de sus pilares es la práctica de la caridad, la promoción de la justicia y, si es preciso, la denuncia profética. Precisamente, por eso, existen también los ministerios referidos a la práctica de la caridad, a la promoción de la justicia y a la denuncia profética.

Frecuentemente, la presencia de la Iglesia en estas áreas se realiza a través del compromiso particular (o colectivo) de los cristianos. Lo normal es que se trate de un "servicio" que - al no estar reconocido eclesialmente ni mediar designación de ninguna clase - no compromete a la Iglesia. Son "servicios" o presencias que se prestan como cristianos, pero no en nombre de la Iglesia.

Sin embargo, también pueden existir ministerios específicamente referidos a la práctica de la caridad, a la promoción de la justicia y a la denuncia profética que se desempeñan en nombre de la Iglesia. Responden a una necesidad permanente y canalizan esta dimensión constituyente y constitutiva de la comunidad cristiana.

Obviamente, concluyen los obispos brasileños, el reconocimiento de esta clase de ministerialidad no invalida la diferenciación entre actuar "cristiano" y "eclesial" en lo social y en lo político. Más bien, la matiza convenientemente, ya 
que si bien es verdad que cuando se actúa como "cristiano" se está respetando la autonomía de la realidad terrestre y la actuación responsable de los bautizados, también lo es que cuando se procede "eclesialmente" se está comprometiendo pública y oficialmente a la iglesia.

\section{La conferencia episcopal de Estados Unidos}

Los obispos estadounidenses parten de la llamada a la santidad de todos los bautizados e indican que si bien es cierto que la mayoría de ellos desarrollan dicha llamada a la santidad en la secularidad, también lo es que algunos lo hacen trabajando en la Iglesia y concentrando sus fuerzas en la edificación de la comunión eclesial que tiene, entre sus objetivos, la transformación del mundo ${ }^{39}$. Estos laicos son tipificados como "ministros eclesiales laicos", indicando que se les reconoce como ministros porque - apelando literalmente a la Instrucción Interdicasterial de 1997 - "prolongan, en el interior y para el mundo, la misión y el ministerio de Cristo" $"$.

Es propio de una eclesiología de comunión - señalan los obispos estadounidenses - que se reconozcan los diversos dones que Dios entrega a la comunidad cristiana y que no se les presente antagónicamente, sino, más bien, como fuente de riqueza de mutua complementariedad. Es cierto que todos los ministerios participan del ministerio de Cristo. Y es igualmente cierto que lo propio del episcopado es - porque se fundamenta en el sacramento del orden-perpetuar el ministerio, constituyente y constitutivo, de los apóstoles. Por eso, todos los ministerios están referidos y relacionados con el ministerio propio de los sucesores de los apóstoles.

Sin embargo, esta incuestionable verdad no puede eclipsar la raíz cristológica y penumatológica de los ministerios laicales, ya que, con palabras del Vaticano II, el Espíritu Santo distribuye gracias especiales entre los fieles de cualquier condición con las que "les hace aptos y prontos para ejercer las diversas obras y deberes que sean útiles para la renovación y mayor edificación de la Iglesia" (LG 12).

Por tanto, todos los bautizados son llamados a servir a la misión de la Iglesia, pero algunos experimentan una posterior vocación específica al ministerio eclesial laical que ha de desarrollarse corresponsablemente con los demás ministerios y, particularmente, con el episcopado.

39. Cfr. United States Conference of Catholic Bishops, Co-Workers in the Vineyard of the Lord, óp. cit. Se pueden encontrar tanto la versión inglesa (http://www.usccb.org/laity/laymin/co-workers.pdf) como la española (http:/www.usccb.org/laity/laymin/CoworkersSpanish.pdf).

40. "Instrucción Interdicasterial 'Ecclesiae de mysterio", óp. cit., Disposiciones prácticas, art. 1 y 2. 
A la luz de estas consideraciones teológicas hay que leer su interés por tipificar el servicio que prestan estos laicos como "ministerio eclesial laical", así como por subrayar "la estrecha colaboración recíproca con el ministerio pastoral de obispos, sacerdotes y diáconos" ${ }^{41}$. Semejante "colaboración recíproca" no les impide reconocer la innegable diferencia entre ministros ordenados y laicales ni su incuestionable complementariedad, ya que prosiguen "en la Iglesia la misión salvífica de Cristo por el mundo"42. El reconocimiento de tal singularidad y complementariedad les habilita para "colaborar con sus pastores en el servicio de la comunidad eclesial"43.

Se agradece que los obispos estadounidenses, una vez asentados estos principios teológicos, tengan un interés especial en emplear una ajustada terminología canónica. Esta inquietud les lleva, por ejemplo, a diferenciar entre "encomendar" y "delegar", "mandar" o "encargar" 44.

Normalmente, el término "encomendar" es empleado para referirse a aquellas personas que desempeñan un oficio en el que se precisa una gran creatividad en cuanto a los programas y a los métodos específicos. Por ejemplo, a un obispo se le "encomienda" una diócesis (CIC 369). Por su parte, puede encomendarse la atención pastoral de una parroquia a un párroco (CIC 515), a varios sacerdotes "in solidum" (CIC 517 \&1) o a un instituto religioso (CIC 520) y también a los diáconos y laicos (CIC $517 \& 2$ ).

En cambio, existe una cierta diversidad para referirse al oficio eclesiástico. En sentido amplio, el "oficio" es semejante a la "tarea" o al "deber" en diversos ámbitos, desde los familiares hasta los relativos a las funciones litúrgicas. Y en sentido más técnico se entiende por "oficio eclesiástico" "todo encargo conferido de manera estable para un fin espiritual" $"$. Por tanto, el concilio no vincula el "oficio" al orden sagrado o a la asignación de una jurisdicción particular. Deja abierta la posibilidad de atribuir también a los laicos determinados oficios, lo que tampoco cierra la posibilidad de que haya "oficios para cuyo ejercicio se requiera la potestad de orden o la potestad de régimen eclesiástico", es decir, que solo puedan ser obtenidos por los clérigos ( $c f r$. C.274, § 1). Obviamente, quienes ejercen oficios eclesiásticos gozan de una cierta estabilidad en dicho oficio. Y lo normal es que las obligaciones y derechos inherentes a un oficio específico queden determinados por el mismo oficio, cesando con la pérdida de dicho oficio.

41. Ibid., Introducción.

42. Ibidem.

43. Ibíd., "I. Fundamentos. A. Describir y responder a realidades nuevas. La llamada de los fieles laicos".

44. Cfr. óp. cit., pp. 54 y ss.: "El nombramiento de los ministerios eclesiales laicos".

45. Decreto Presbyterorum ordinis sobre el ministerio y la vida de los presbiteros, 20. Cfr. CIC $145 \& 1$. 
Habitualmente, se emplea el término "mandato" cuando se nombra a alguien para una instancia específica o cuando se recibe una responsabilidad relativa a un oficio que esa persona no desempeña.

La "delegación" se refiere a una situación en la que la persona que tiene un poder ejecutivo ordinario en virtud de un oficio permite que dicho poder sea ejercido por otra persona en situaciones generales o específicas.

\section{El directorio de la Diócesis de Bilbao (2006)}

Una vez reconocida la importancia y calidad teológica de las conferencias episcopales brasileña y estadounidense, es preciso indicar que se trata de dos excepciones - notables, pero excepciones - en el panorama actual. La tendencia de fondo la viene marcando la Instrucción Interdicasterial de 1997 cuando invita a abandonar la tipificación del servicio pastoral del laicado como "ministerio".

Por eso, no extraña que el "Directorio de los laicos y laicas con encargo pastoral" de la Diócesis de Bilbao, España, entienda el ministerio que prestan los laicos como "colaboración", "participación", "asociación" o "cooperación" en la misión y tareas del ministerio ordenado ${ }^{46}$. Es el precio - no solo semánticoque hay que pagar por no entender la ministerialidad laical como participación en la misión de Cristo en la iglesia y en el mundo (algo que deriva del bautismo) y por no articularla con el ministerio ordenado desde semejante cimiento. La amortiguada presencia de este capital punto en los apartados más teológicos en dicho directorio explica la ausencia de una creativa recepción de la ministerialidad laical a partir de su fundamento en Cristo Sacerdote, Profeta y Rey y, por tanto, como participación en la misión de Cristo en la iglesia y en el mundo.

Es más, se trata de un descuido que no sólo imposibilita una equilibrada articulación entre dicha ministerialidad laical y el sacerdocio ordenado, sino que propicia el retorno a un modelo organizativo y a una concepción de la iglesia - se quiera o no- más autoritativa y verticalista que corresponsable y, por ello, más cercana a la eclesiología imperante antes del concilio que a la promulgada por el Vaticano II.

46. Cfr. Diócesis de Bilbao, "Directorio de laicos y laicas con encargo pastoral", Boletín Oficial (574), marzo 2006, pp. 203-225, n. ${ }^{\circ} 29$ : “La pertenencia al pueblo de Dios es por sí misma el fundamento para que los laicos puedan asumir responsabilidades en la comunidad cristiana, con dedicación total o parcial, coyuntural o permanente, pudiendo llegar a participar en la misión del ministerio ordenado y en sus tareas". Cfr. ibid., n. ${ }^{\circ}$ 33: El reconocimiento de la disponibilidad que manifiestan algunos laicos para vincular "con notable estabilidad su proyecto de vida al servicio pastoral" "no les convierte en pastores", sino, más bien, en "laicos [...] asociados al ministerio pastoral". 
El primero de estos modelos eclesiológicos enfatiza la importancia de la comunión del "cuerpo" con la "cabeza" y descuida una concepción y praxis comunional más cuidadosa de la reciprocidad entre ambas ("perijóresis").

Esto último es algo que asoma cuando sostiene que "la pertenencia al pueblo de Dios es por sí misma el fundamento para que los laicos puedan asumir responsabilidades en la comunidad cristiana" 47 . Es cierto lo que sostiene, pero al no articular debidamente la fundamentación eclesiológica con la cristológica, acaba refundando la ministerialidad laical en dicha pertenencia eclesial (por cierto, marcadamente jerárquica y autoritativa) y no en el bautismo. Es así como se propicia la comprensión de dicha ministerialidad como una "participación" en la responsabilidad pastoral propia de los presbíteros; no como ejercicio ministerial de raíz cristológica que ha de desempeñarse corresponsablemente. La consecuencia de todo ello es que no solo se diluye la deseable corresponsabilidad eclesial, sino que la misma comunión eclesial acaba siendo reconducida a una comprensión más vertical que "perijorética".

Es cierto que en otro número del Directorio se sostiene -inspirándose en aportaciones emanadas de la conferencia episcopal francesa- que "la relación directa del servicio de estas personas a la comunidad y a su misión de forma estable y con un reconocimiento público, habla de su gran densidad simbólica, ya que significan a su manera el servicio de Cristo al pueblo de Dios y representan a la Iglesia en el mundo" 48 . Interesante y equilibrada formulación identitaria en la que desgraciadamente no se abunda y que, precisamente por ello, acaba siendo irrelevante tanto en el cuerpo doctrinal como operativo del Directorio.

Es muy probable que la fundamentación de la ministerialidad laical como "participación" o "asociación" con la misión del ministerio ordenado - y no en el bautismo- obedezca a la urgencia por disponer cuanto antes de un directorio. Sin embargo, tal encomiable voluntad no invalida que el Directorio de la Diócesis de Bilbao - al estar redactado a la sombra de la teología del laicado, restrictiva y preconciliar, que recoge la declaración Interdicasterial de 1997acabe canalizando un incontenido temor a que la ministerialidad laical suponga, a la corta o a larga, la infravaloración y posterior desaparición de la singularidad propia del ministerio ordenado.

Ésta parece ser también la sombra alargada que se cierne sobre el Directorio y que acaba marcándolo más de lo que parece a simple vista.

\section{La secularidad presbiteral}

Pero en la recepción de la teología laical y presbiteral del Vaticano II aparece una segunda cuestión íntimamente conectada con la ministerialidad y de enorme 
importancia para la comunidad cristiana: la reivindicación de la índole secular como algo "propio y peculiar de los laicos" (LG 31), dando a entender que es algo exclusivo de ellos.

Es muy interesante recordar, en primer lugar, el debate sobre esta cuestión entre B. Forte, S. Dianich y G. Lazzati en la fase de recepción eclesial más creativa de la teología del laicado ${ }^{49}$.

G. Lazzati sostiene -iniciando una clase de discurso teológico que parece haber hecho fortuna entre algunos sectores eclesiales - que la "índole secular" no es generalizable ni atribuible a toda la iglesia, ya que si así fuera se diluiría la responsabilidad específica de los laicos en el mundo.

Por su parte, B. Forte y S. Dianich argumentan que lo "propio" del laicado no viene determinado ni por una misión ni por el empleo de unos determinados medios, sino por el bautismo, en cuya gracia se encuentra la consagración y el fundamento de su misión. Del bautismo brotan positivamente toda una serie de carismas y ministerios que son dados para ser recibidos por la comunidad. Por tanto, toda la iglesia (sacerdotes, religiosos y laicos) es secular y es toda la Iglesia la que ha de hacerse presente en la secularidad. Consecuentemente, ha de desterrarse el miedo a una existencia, a la vez, consagrada a Dios y contingente en el mundo.

Sorprende, a la luz de este debate postconciliar, que el Directorio de la Diócesis de Bilbao sostenga - refiriéndose a los laicos que ejercen un ministerio - que "la encomienda pastoral no recorta la condición laical y su secularidad específica, que sigue determinando teológicamente los servicios y tareas" ${ }^{50}$. Y sorprende porque no tiene presente ni la secularidad "propia" de todo bautizado ni la del ministerio ordenado ni, por tanto, presta atención alguna a la necesidad de su articulación con la "propiamente"laical.

Por eso, resulta particularmente interesante traer a colación, en segundo lugar, la aportación de la conferencia episcopal brasileña sobre la ministerialidad y la secularidad que prolonga el debate reseñado entre S. Dianich, B. Forte y G. Lazzati.

No es procedente separar - afirman los obispos brasileños - "Iglesia" y "mundo" ni la "vida interna de la comunidad cristiana" de la "misión" de la Iglesia en el mundo. De la misma manera, tampoco tiene sentido distinguir y separar el apostolado laical en el interior de la Iglesia ("ad intra") del realizado

49. Cfr. J. Martínez Gordo, "Ser laico en la Iglesia", Razón y fe 1292 (2006), pp. 437-451; "La identidad laical en el postconcilio", Lumen 4-5 (2006), pp. 301-328; "La teología conciliar sobre el laicado: aciertos, ambiguiedades y consecuencias", Surge 635 (2006), pp. 171-189.

50. Diócesis de Bilbao, "Directorio de laicos y laicas con encargo pastoral", óp. cit., n. ${ }^{\circ} 36$. 
en las 1lamadas realidades temporales ("ad extra"), ya que se trata de dos dimensiones igualmente radicadas en la única misión de todo bautizado y, por ello, complementarias la una de la otra.

El reconocimiento de la sacramentalidad de la Iglesia les lleva a sostener que cuando empleamos expresiones tales como la "misión de la Iglesia" o "ministerio de la Iglesia" nos estamos refiriendo a un único dinamismo que engloba tanto la vida interna de la Iglesia como su actuación en el mundo. Y en coherencia con ello, lo propio de todo bautizado es estar presente en el mundo y escuchar, a la vez, el Espíritu de Cristo en el Evangelio, en la celebración de la liturgia y en el encuentro con las personas humanas, especialmente con los pobres. Por tanto, "la misión de la Iglesia no es responsabilidad de algunos, sino de todos" 51 . Precisamente, por ello, se puede hablar de una "Iglesia toda ella ministerial" o de "corresponsabilidad diferenciada". Igualmente se puede afirmar que "todos somos responsables en la Iglesia" o de "Iglesia con responsabilidades apostólicas compartidas", de "comunidad enviada al servicio", de "comunión y participación" (Puebla) y de "comunión y misión" (CNBB) ${ }^{52}$. Son muchos los laicos y laicas que testimonian la consistencia de esta articulación entre misión y ministerio. Y lo hacen comprometiéndose en favor de la justicia y de la paz y, al mismo tiempo, prestando innumerables servicios o ministerios con generosidad y competencia.

Por tanto, hay que superar el viejo esquema preconciliar de servicio o ministerio en el interior de la Iglesia ("ad intra") y compromiso secular en el mundo ("ad extra"). A la luz de la teología del Vaticano II no es necesario "salir" de la Iglesia para ir al mundo, de la misma manera que no es necesario "salir" del mundo para "entrar" y "vivir" en la Iglesia ${ }^{53}$. Sencillamente, porque los laicos a los que se les confía un ministerio eclesial son y siguen siendo laicos. Viven la ministerialidad en relación con Cristo y con la Iglesia y de manera particular con el mundo, es decir, como laicos que ejercen la misión del pueblo cristiano "en la Iglesia y en el mundo"s4.

El debate postconciliar sobre lo "propio y peculiar" de los laicos permite concluir que se ha entender por tal la vocación laical, es decir, la invitación a vivir coherentemente la fe profesada en la existencia cotidiana, algo que, obviamente, es propio de todo bautizado y de cualquier cristiano ${ }^{55}$.

51. Conferência Nacional dos Bispos do Brasil, Missão e ministérios dos cristãos leigos e leigas, óp. cit., n. ${ }^{\circ} 77$.

52. Cfr. ibidem.

53. Cfr. ibid., n. ${ }^{\circ} 90$.

54. Ibid., n. ${ }^{\circ} 98$.

55. Cfr. ibid., n. ${ }^{\circ} 100-101$. 
A la luz de esta concepción de la "secularidad", se entiende que los obispos brasileños la comprendan de diferentes y complementarias maneras ${ }^{56}$.

En primer lugar, como "secularidad" del mismo mundo: la realidad terrena y la sociedad gozan de propias leyes y valores que el hombre ha de descubrir, emplear y ordenar poco a poco (cfr. GS $36 \mathrm{~b}$ ).

Pero existe, en segundo lugar, una "laicidad" de la misma Iglesia, ya que es toda ella la que está en el mundo y la que participa de sus actividades en todos los campos, a pesar de que sean muy diversificadas las relaciones que tejen la vida humana: familia, economía, sociedad, política, cultura, religiones, etc.

Es incuestionable la existencia, en tercer lugar, de una "índole secular" propia y peculiar de los laicos y de las laicas (cfr. LG 31) que los vincula "especialmente" con el mundo para hacer presente a la iglesia en aquellos sitios a los que ella no puede llegar. Todo laico es al mismo tiempo $-y$ en virtud de los dones que se le han concedido - testigo e instrumento vivo de la propia misión de la Iglesia (cfr. LG 33b. EN 70).

Y existe, finalmente, una "laicidad en la Iglesia" que consiste en vivir en su seno aquellos valores (llamados "laicos" en Occidente, pero de raíz cristiana) que son la referencia ideal para la convivencia en la sociedad civil (libertad, fraternidad, solidaridad e igualdad). Evidentemente, son valores potenciados por la Iglesia pero que no siempre tienen plena vigencia en la vida y en las relaciones intraeclesiales.

La ampliación de horizontes que traen los obispos brasileños converge con el interés de los prelados estadounidenses por superar tanto la "clericalización" del laicado (que acertadamente denuncia el Directorio de la Diócesis de Bilbao) como su "secularización" (en la que desgraciadamente acaba incurriendo) con el fin de ofrecer una "católica" articulación entre secularidad y ministerialidad.

"En nuestra época - sostienen los obispos de Estados Unidos - han surgido los ministros eclesiales laicos, hombres y mujeres que trabajan en colaboración con obispos, sacerdotes, diáconos y otros laicos, cada uno de ellos respondiendo a los carismas concedidos por el Espíritu. Debido a su carácter secular, en un modo particular ellos 'son la Iglesia en el corazón del mundo y traen al mundo al mismo corazón de la Iglesia' al atender a las necesidades de la comunidad actual"57.

Una feliz formulación en la que se reconoce no solo la raíz penumatológica de los ministerios laicales, sino sobre todo la secularidad "propia" de ministerialidad laical.

56. Cfr. ibid., n. ${ }^{\circ} 107$.

57. Cfr. United States Conference of Catholic Bishops, Co-Workers in the Vineyard of the Lord, óp. cit., versión española, p. 22, citando a USCCB, Subcomité para el ministerio laico, "El Ministerio Laico de la Iglesia: El Estado de las Interrogantes" (Washington D. C., USCCB, 2001), n. ${ }^{\circ} 15$. 
Como contrapartida, el Directorio de la Diócesis de Bilbao no tiene presente ni el debate entre G. Lazzati, S. Dianich y B. Forte ni las matizadas articulaciones y sugerentes aportaciones que proponen las conferencias episcopales de Brasil y de los Estados Unidos.

Todo un preocupante olvido que facilita la vuelta a una visión preconciliar de la Iglesia y que corre un alto riesgo de sancionar como teológica lo que no pasa de ser una decisión de estrategia pastoral tomada por los padres sinodales en 1971: "se debe dar al ministerio sacerdotal, como norma ordinaria, tiempo pleno", lo que quiere decir que "la participación en actividades seculares de los hombres no puede fijarse de ningún modo como fin principal, ni puede bastar para reflejar toda la responsabilidad específica de los presbíteros" $" 58$. Se trata de una decisión que intenta optimizar el debilitado número de efectivos pastorales sin negar - porque no lo puede hacer- la posibilidad de un compromiso secular en determinadas circunstancias y, evidentemente, con el consentimiento del obispo. La autoridad magisterial de LG sigue siendo mucho más consistente - también formalmente - que esta directiva práctica.

Por tanto, la secularidad también es una dimensión constitutiva y constituyente del presbítero y del religioso, como bautizados que son. Obviamente, ha de ser prudentemente modulada, pero jamás negada y, siempre, articulada con la que es "propia" del laico que ejerce un ministerio laical.

\section{Elogio de la "catolicidad"}

Una buena parte de la teología sobre el laicado y, sobre todo, la gran mayoría de las decisiones pastorales que se están tomando, presentan dificultades para superar críticamente el diagnóstico del sector mayoritario de la curia vaticana sobre el momento actual del ministerio ordenado y su relación con la ministerialidad laical; algo que, afortunadamente, se supera en las aportaciones de los obispos de Estados Unidos y de Brasil.

Semejante dependencia explica que se haya asumido la apuesta vaticana por recuperar una concepción "sacralizante" del ministerio ordenado y otra más "secularizante" del laicado; una concepción — no se puede olvidar - que acaba sintonizando más con los acentos teológicos y pastorales preconciliares que con los propiamente conciliares.

La asunción de tales concepciones - y la estrategia que le es propia - está llevando a proponer una articulación escasamente "católica" entre la ministerialidad laical (participación en la misión de Cristo en la iglesia y en el mundo, gracias al bautismo) y la identidad y espiritualidad propias del ministerio ordenado (cimentada en el sacramento del orden).

58. Sínodo de los Obispos 1971, Documentos, óp. cit., p. 19. 
Todo ello trae como consecuencia el apuntalamiento de una eclesiología verticalista (el laico recibe un "encargo" para participar en la misión del ministerio ordenado, pero no se le "confía" o "encomienda" una responsabilidad pastoral) en detrimento de la eclesiología corresponsable del Vaticano II (la ministerialidad laical se funda en el bautismo y en la participación en la triple función de Cristo como sacerdote, profeta y rey y, por tanto, en su misión en la iglesia y en el mundo).

Pero, al reivindicar la secularidad como lo propiamente laical, no solo se descuida que dicha secularidad sea nota constitutiva y constituyente de todo bautizado y de toda comunidad cristiana, sino que se acaba aparcando que el mismo ministerio ordenado es y no puede dejar de ser secular.

Un preocupante descuido de enormes consecuencias. 